\title{
The impact of microfinance programmes on access to health care, knowledge to health indicators and health status among women in Moshi, Tanzania
}

\author{
CHRISTOPHER MTAMAKAYA ${ }^{1,2^{*}}$, JOACHIM KESSY ${ }^{3}$, DAMIAN JEREMIA ${ }^{3}$, SIA MSUYA ${ }^{3}$ and BABILL STRAY- \\ PEDERSEN ${ }^{1,4}$ \\ ${ }^{1}$ Institute of Clinical Medicine, University in Oslo Norway \\ ${ }^{2}$ Department of Health, Moshi Municipal Council, Moshi Tanzania \\ Institute of Public Health, Kilimanjaro Christian Medical University College, Moshi Tanzania \\ ${ }^{4}$ Division of Women and Children, Oslo University Hospital Rikshospitalet, Norway
}

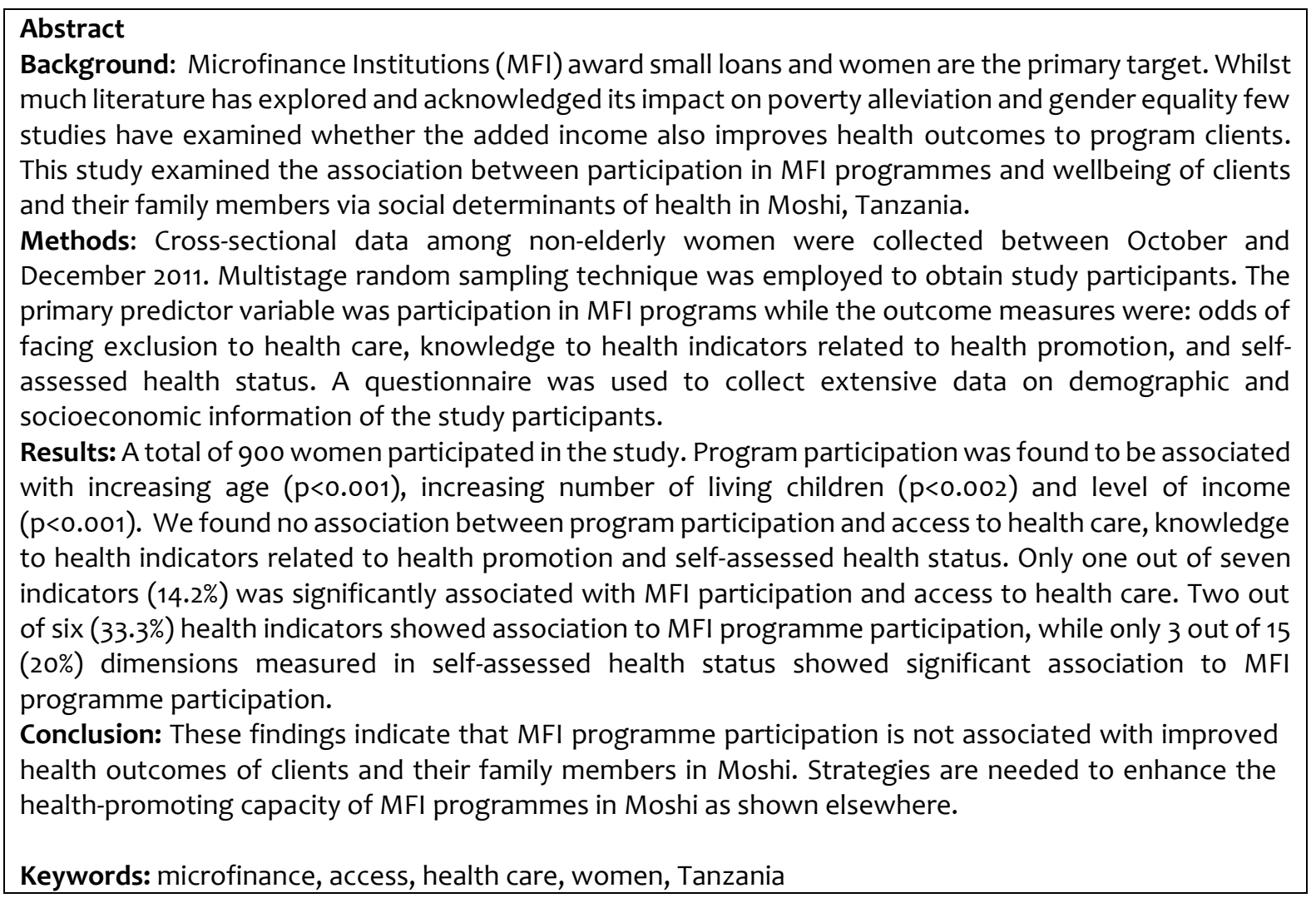

\section{Introduction}

Poverty and health inequalities are inextricably linked. Poverty impacts on individuals' health, including the ability and opportunity to engage in health-seeking and health promoting behaviour (Pronky et al., 2007). Microfinance is one example of an intervention that can give a considerable impetus through poverty reduction and its associated vulnerabilities including the fundamental determinants of health disparities (WHO, 2008). The relationship between social determinants of health and health is known to contribute to health disparities such that people with a lower socioeconomic status experience poor health (Marmot, 2007). Most often women with low education attainment and minimum levels of self-esteem living in exploitative conditions are less likely to seek out preventive health care and acquire better health (Wamue-Ngare \& Njoroge, 2011). According to Wamue-Ngare \& Njoroge (2011), this intertwining is more prevalent in the low-income

\footnotetext{
* Correspondence Email: cmtamakaya@hotmail.com
} 
countries where women have repressive social relationship within rigid and hierarchical social structures.

Policy makers have consistently called upon for interventions to improve socio-economic status as means to address the fundamental determinants of health disparities. Responding to the call, a significant development has been triggered of community based organizations and initiatives at the local level to improve the socioeconomic status of the disadvantaged populations. These self-help programmes in the form of saving and credit popularly known as microfinance programmes, have succeeded in changing their lives, enhancing incomes and generating other positive externalities (Ahmed, 2009). Microfinance Institutions (MFI) award small loans and women are the primary target based on theoretical assumption that they are more likely to be credit constrained than men, have restricted access to the wage labour market, have an inequitable share of power in household decision-making, too poor or remotely located to take advantage of traditional financial services and that they lack capital to invest in their business which could allow them to improve their family living standard (Woller, 2001; Yunus, 2002). Participation in MFI can improve socioeconomic status by improving economic wellbeing and addressing fundamental determinates of health disparities among women (Marmot et al., 2008).

To date the main drive of research in the field of microfinance has been in relation to its effect on poverty alleviation, gender equality or financial control within the lending institutions (Sigalla \& Carney, 2012). Whilst much literature has explored its impact on poverty and gender, few studies have examined whether the added income also improves wellbeing of the clients. Furthermore, the few studies exploring the MFI and health link have reported mixed results. A study from India (Mohindra et al., 2008) found no association between programme participation and self-assessed health. In the Dominican Republic, Dohn et al. (2004) reported an improvement in health knowledge and dietary quality with no changes in anthropometric measures. But other studies have contended that MFI have been associated with improved health outcomes of clients. For example, Mohindra et al. (2008) found lower levels of emotional stress among MFI clients compared to non-clients. Smith (2002) found improved maternal and child health while Doocy et al. (2005) showed a positive impact on the nutritional status of participants and their families.

Unlike other developing countries like Pakistan and Bangladesh (Khandker,2005; Pitt \& Khandker, 1998; Goetz \& Gupta 1996; Mohindra et al., 2008), where the potential of MFI has been extensively explored, little evidence exist in the cultural and political context of Tanzania despite the growth of the programmes (Kessy et al., 2015). This study aimed to explore the impact of participation in MFI programme on access to health care, knowledge to health indicators related to health promotion and self-assessed health status to programme participants and their family members via social determinants of health.

\section{Material and Methods}

\section{Study site and design}

This cross-sectional study was conducted from October-December 2011 in Moshi Urban district, northern Tanzania. Moshi has a projected population of about 200,000 (URT, 2013) living in around 33,910 households with $40 \%$ of the population living below the poverty line (i.e. living below US\$ 1 per day). The district is sub- divided into 15 wards of which 5 are regarded as urban and 10 as periurban. The study was conducted in the peri-urban area that has high population density with limited access to formal financial institutions - an area where more than 50 microfinance institutions (MFI) were operating.

\section{Study population and sampling}


The population for this study included women aged 18-60 years who were residents of Moshi irrespective of their MFI programmes membership status. We excluded women who were not permanent residents of Moshi and those who did not give a written consent. Sample size estimation and sampling procedure for this study have been described elsewhere (Kessy et al., 2015). It was estimated using computer software EpiCalc 2000 accounting for the national financial accessibility which covers about 40\% (Fin Scope Survey, 2009) with 5\% significance level and $80 \%$ power, the minimum sample size was estimated to be 900 women. Selection of study participant's involved the use of multistage random sampling technique. The first stage randomly selected five out of ten peri-urban wards. Thereafter random selection of three neighbourhoods from each of the five wards was conducted, giving a total of 15 neighbourhoods. All women meeting the eligibility criteria in households of the selected neighbourhoods were invited to participate.

\section{Data collection}

Face to face interviews were conducted with consented women by trained research assistants. A questionnaire was used to collect information on social-demographic characteristics, socioeconomic status and on MFI participation status. Detailed information about microcredit programmes were obtained on type of women enrolled, financial and non-financial services received, payment schedule and conditions attached to the credit. Information on perceived advantages and challenges in using such programmes were also collected. Questions on key variables were the same as those used in the Tanzania Demographic and Health Survey (TDHS, 2011). Pre-testing of the data collection tool was conducted in wards which were not part of the study sites but with comparable characteristics.

Six health indicators related to health promotion and exclusion time to health care during a one year period prior to the study were used as proxy for better health outcomes. Health indicators related to health promotion included three questions on knowledge and three questions on health behaviours. Exclusion to health care was determined by enquiring about barriers at household level that resulted into failure to utilize health care. Eight situations were explored in which household members were forced to fail to access health care. Exclusion was defined as at least one situation over the past 12 months of failure to access medical services to any of the followings; a sick child, a sick adult, an elderly member, a family member, a failed or delay in hospitalization/ surgery or of family members

Health achievement was self-assessed using 15Dimension (15D) instrument- a generic, comprehensive, 15-dimensional, standardized, self-administered measure of health-related quality of life (HRQoL) developed by Sintonen (2001). Respondents were interviewed on the 15 dimensions to self asses and rate their physical, mental and social aspect of health. Each dimension has 5 levels by which more or less of the attributes are distinguished and respondents were asked to choose the level which best describes their present health status. A single index score on a 0-1 scale is used to calculate and represent the respondents HRQoL profile on each dimension. A maximum score of 1 means no problem while a score of o equals to being dead.

\section{Data analysis}

Questionnaires were checked for completeness and consistency on daily basis during data collection period. Data were entered, cleaned, and analysed using Statistical Package for Social Sciences Version 22 (IBM Corp, NY). Frequency and Proportions were used to summarize category data whilst median and range were used to summarize continuous data, chi-square tests was used for bivariate comparison between categorical variables. Adjusted Odds Ratio (AOR) with their corresponding $95 \% \mathrm{Cl}$ was used to calculate the strength of association between knowledge to health indicators and dependent variable while $15 \mathrm{D}$ self-assessed participants' health. Logistic regression analysis was used to determine independent predictors of programme participation and various aspects of women wellbeing. The $\rho$-value was two tailed, and value of less than 0.05 indicated the statistical significance of the findings. 


\section{Ethical considerations}

The study was ethically approved by research and ethical committees of Kilimanjaro Christian Medical (KCM) University College of Moshi Tanzania (ethical clearance. No 303) as well as from regional ethical committee of South East, Norway (REK No 2011/1358). Permissions to conduct the study were granted by Moshi Municipal Director. Informed written consent was obtained from the participants after the researchers explained the purpose of the study. Participants were informed of their right to refuse participation in the study and were assured of the confidentiality of the collected information by assigning unique identification number.

\section{Results}

\section{Baseline characteristics of the respondents}

Out of a total of 1100 women approached 900 gave written consent and participated in the study giving a response rate of $81 \%$. The median age of the participants at enrolment was 36 years, ranging from $18-60$ years. Among them, $766(85.1 \%)$ had primary education, $644(71.7 \%)$ were married or cohabiting, 829(92\%) had no formal employment, 296 (40.2\%) were low income earners (below \$1 per day) 540(63\%) lived in household with 3-5 members and $455(52.0 \%)$ had more than 2 living children. A total of $346(38 \%)$ were clients of the MFI programme (participants of MFI). Programme participation was found to be associated with increasing age $(P<0.001)$, increasing number of living children $(P<0.002)$ and level of income $(P<0.001)$. Furthermore programme participation is found high (57.7\%) in middle income group (US\$30-100 per month equivalent 1-3 USD per day) compared to low income group (32.8\%) who earned less than US\$30 per month (Table 1).

Table 1: Socio-demographic characteristics of women by participation status in microfinance programmes in Moshi urban ( $\mathrm{N}=900)$

\begin{tabular}{|c|c|c|c|c|c|}
\hline \multirow[t]{2}{*}{ Characteristics } & \multirow[t]{2}{*}{ Response } & \multicolumn{4}{|c|}{ Participation status } \\
\hline & & Total & $\begin{array}{l}\text { Clients } \\
\mathrm{n}(\%)\end{array}$ & $\begin{array}{l}\text { Non-clients } n \\
(\%)\end{array}$ & P-value \\
\hline \multirow[t]{5}{*}{ Age in years $(n=886)$} & $\leq 19$ & 31 & $2(6.5)$ & $29(93.5)$ & \\
\hline & $20-29$ & 223 & $60(26.9)$ & $163(73.1)$ & \\
\hline & $30-39$ & 303 & $115(38.0)$ & $188(62.0)$ & $<0.001$ \\
\hline & $40-49$ & 223 & $113(50.7)$ & $110(49 \cdot 3)$ & \\
\hline & $50-59$ & 106 & $53(50.0)$ & $53(50.0)$ & \\
\hline \multirow[t]{4}{*}{ Education $(n=900)$} & Never attended & 29 & $7(24.1)$ & $22(75.9)$ & \\
\hline & Primary level & 766 & $294(38.4)$ & $472(61.6)$ & 0.084 \\
\hline & Secondary level & 92 & $38(41.3)$ & $54(58.7)$ & \\
\hline & Higher & 13 & $7(53.8)$ & $6(46.2)$ & \\
\hline \multirow[t]{3}{*}{ Marital status $(\mathrm{n}=898)$} & Married/cohabiting & 644 & $246(38.2)$ & $398(61.8)$ & \\
\hline & Separated/widow/divorced & 167 & $73(43.7)$ & $94(56.3)$ & 0.097 \\
\hline & Single & 87 & $26(29.9)$ & $61(70.1)$ & \\
\hline \multirow{4}{*}{$\begin{array}{l}\text { Monthly income in US\$ } \\
(\mathrm{n}=737)\end{array}$} & & & & & \\
\hline & $<30$ & 296 & $97(32.8)$ & $199(67.2)$ & \\
\hline & $30-100$ & 298 & $172(57.7)$ & $126(42.3)$ & $<0.001$ \\
\hline & $>100$ & 143 & $61(42.7)$ & $82(57.3)$ & \\
\hline \multicolumn{6}{|l|}{ Number of living } \\
\hline \multirow[t]{4}{*}{ children $(n=875)$} & 0 & 19 & $4(21.1)$ & $15(78.9)$ & \\
\hline & $1-2$ & 401 & $134(33.4)$ & $267(66.6)$ & \\
\hline & $3-4$ & 299 & $129(43.1)$ & $170(56.9)$ & 0.002 \\
\hline & More than 5 & 156 & $69(44.2)$ & $87(55.8)$ & \\
\hline \multirow[t]{3}{*}{$\begin{array}{l}\text { Number of households } \\
(\mathrm{n}=857)\end{array}$} & 1-2 people & 85 & $27(31.8)$ & $58(68.2)$ & \\
\hline & 3-5 people & 540 & $206(38.1)$ & $334(61.9)$ & 0.091 \\
\hline & More than 5 & 232 & $110(42.0)$ & $152(52.0)$ & \\
\hline
\end{tabular}




\section{Microcredit participation and access to care}

Only one indicator describing access to surgical care was significantly associated with MFI participation (Table 2). A high proportion of programme participants (66.7\%) who had a family member recommended for surgery in the past six months failed to obtain the service $(P=0.032)$. Other indicators; sick child failed to obtain care $(p=0.422)$, sick adult failed to obtain care $(p=0.155)$, sick elderly failed to obtain care $(p=0.279)$, member with chronic illness failed to obtain care $(p=0.469)$ and family member failed recommended hospitalization $(p=0.120)$, were not significantly associated with programme participation.

Table 2: Participation in microfinance programmes and its association with access to care during the past six months $(\mathrm{N}=900)$.

\begin{tabular}{|c|c|c|c|c|c|}
\hline \multirow[b]{2}{*}{ Items } & \multirow[b]{2}{*}{ Total } & \multicolumn{2}{|c|}{ Participation in MFI } & \multirow[b]{2}{*}{$\chi^{2}$} & \multirow[b]{2}{*}{ P-value } \\
\hline & & $\frac{\mathrm{N}(\%)^{\star}}{\text { Non-clients }}$ & Client & & \\
\hline Any sick child failed to obtain health care & 28 & $15(2.7)$ & $13(3.8)$ & 0.629 & 0.526 \\
\hline Any sick adult failed to obtain health care & 39 & $20(3.6)$ & $19(65.5)$ & 2.025 & 0.155 \\
\hline \multicolumn{6}{|l|}{ Any sick elderly member failed to obtain health } \\
\hline $\begin{array}{l}\text { Any person with chronic illness failed to obtain } \\
\text { health care }\end{array}$ & 25 & $16(2.9)$ & $9(2.6)$ & 0524 & 0.469 \\
\hline $\begin{array}{l}\text { Any family member was recommended a } \\
\text { hospitalisation but failed to obtain such care }\end{array}$ & 18 & $14(2.5)$ & $4(1.2)$ & 2.416 & 0.120 \\
\hline $\begin{array}{l}\text { Any member was recommended a surgery but } \\
\text { failed to be obtain such care }\end{array}$ & 15 & $5(0.9)$ & $10(2.9)$ & 4.583 & 0.032 \\
\hline
\end{tabular}

*Column percent

\section{Microcredit participation and health knowledge}

As shown in table 3, Programme participation was found to be associated with increase in health knowledge in preparation and use of Oral Rehydration Salt (ORS) and knowledge on breast cancer and importance of self-examinations only. The MFI clients had 2.17 folds increase odds of being knowledgeable on stages of ORS preparation and duration for use after being prepared compared to non-clients ( $\mathrm{OR}=2.1795 \% \mathrm{Cl}, 1.10-4.62)$. Furthermore, MFI clients had 1.37 folds increase odds in knowledge on breast cancer and importance of self-examination compared to non-clients $(\mathrm{OR}=1.37,95 \% \mathrm{Cl}, 1.01-1.86)$. Despite not significantly associated with MFI participation, clients had $38 \%$ less odds of being knowledgeable on hand washing compared to non-clients $(\mathrm{OR}=0.62,95 \% \mathrm{Cl}$, 0.08-4.67).

\section{Microcredit participation and participants self-assessed health using 15D}

As shown in table 4, we found no significant difference in association between clients and nonclients in self-assessed health status scores in most of the dimensions asked, both respondents scored high with no significance different between the two groups; 13 out of 15 (87\%) of the dimensions explored revealed the respondents (both clients and non-clients) to have no problems with no significant difference. Only in three dimensions(20\%); Mobility $96.6 \%$ vs. $89.9 \%$ (p-value 0.001), Vision 93.1\% vs.89.9\% (p-value 0.001) and Discomfort 98.4\% vs. 91.4\% (p-value 0.001) clients scored higher but with significant difference compared to non-clients. 
Table 3: Distribution of respondents according to knowledge on health indicators related to health promotion by participation in MFI

\begin{tabular}{|c|c|c|c|c|}
\hline Health indicator & $\mathbf{n}$ & Clients, n(\%) & Non-client, $\mathrm{n}(\%)$ & AOR $(95 \% \mathrm{Cl})$ \\
\hline Reasons for water purification $(n=882)$ & $871(98.8)$ & $338(97.7)$ & $533(96.2)$ & $2.85(0.59-27.27)$ \\
\hline $\begin{array}{l}\text { Stages of ORS preparation and } \\
\text { duration for use after being prepared } \\
(\mathrm{n}=885)\end{array}$ & $803(93.9)$ & $324(93.8)$ & $479(86.4)$ & $2.17(1.10-4.62)$ \\
\hline Signs of a sick child $(\mathrm{n}=881)$ & $873(99.1)$ & $338(97.6)$ & $535(96.6)$ & $1.05(0.20-6.82)$ \\
\hline Hand washing $(n=896)$ & $890(99.3)$ & $341(98.5)$ & $549(99.1)$ & $0.62(0.08-4.67)$ \\
\hline $\begin{array}{l}\text { Cervical cancer and pap smear test } \\
(\mathrm{n}=842)\end{array}$ & $101(12.0)$ & $41(11.9)$ & $60(10.8)$ & $1.05(0.67-1.64)$ \\
\hline $\begin{array}{l}\text { Breast cancer and the importance of } \\
\text { self-examination }(n=844)\end{array}$ & $871(98.8)$ & $327(94.5)$ & $474(98.2)$ & $1.37(1.01-1.86)$ \\
\hline
\end{tabular}

*Column percent

Table 4: Self-perceived health by dimension and participation by percentage in $\mathrm{MFI}(\mathrm{N}=900)$

\begin{tabular}{|c|c|c|c|c|c|}
\hline \multirow[b]{2}{*}{ EQ 15 dimension } & & \multicolumn{3}{|l|}{ Participation status } & \multirow[b]{2}{*}{ P-Value } \\
\hline & & $\begin{array}{l}\text { Non participates (non- } \\
\text { clients) }\end{array}$ & $\begin{array}{l}\text { Participate } \\
\text { (clients) }\end{array}$ & MFI & \\
\hline \multirow[t]{2}{*}{ Mobility } & No problem & 89.9 & 96.6 & & 0.001 \\
\hline & Any problem & 10.1 & 3.4 & & \\
\hline \multirow[t]{2}{*}{ Vision } & No problem & 82.6 & 93.1 & & 0.001 \\
\hline & Any problem & 17.4 & 6.9 & & \\
\hline \multirow[t]{2}{*}{ Hear } & No problem & 99.1 & $99 \cdot 5$ & & NS \\
\hline & Any problem & 0.9 & 0.5 & & \\
\hline \multirow[t]{2}{*}{ Breathing } & No problem & 97.1 & $99 \cdot 3$ & & NS \\
\hline & Any problem & 2.9 & 0.7 & & \\
\hline \multirow[t]{2}{*}{ Sleeping } & No problem & 98.8 & 98.9 & & NS \\
\hline & Any problem & 1.2 & 1.1 & & \\
\hline \multirow[t]{2}{*}{ Eating } & No problem & 100.0 & 99.6 & & NS \\
\hline & Any problem & 0.0 & 0.4 & & \\
\hline \multirow[t]{2}{*}{ Speech } & No problem & 100.0 & 100.0 & & NS \\
\hline & Any problem & 0.0 & 0.0 & & \\
\hline \multirow[t]{2}{*}{ Elimination } & No problem & 100.0 & 99.5 & & NS \\
\hline & Any problem & 0.0 & 0.5 & & \\
\hline \multirow[t]{2}{*}{ Usual activity } & No problem & 99.1 & 99.1 & & NS \\
\hline & Any problem & 0.9 & 0.9 & & \\
\hline \multirow[t]{2}{*}{ Mental function } & No problem & $99 \cdot 4$ & $99 \cdot 3$ & & NS \\
\hline & Any problem & 0.6 & 0.7 & & \\
\hline \multirow[t]{2}{*}{ Discomfort } & No problem & 91.2 & 98.4 & & 0.001 \\
\hline & Any problem & 8.8 & 1.6 & & \\
\hline \multirow[t]{2}{*}{ Depression } & No problem & 96.5 & $97 \cdot 3$ & & NS \\
\hline & Any problem & $3 \cdot 5$ & 2.7 & & \\
\hline \multirow[t]{2}{*}{ Distress } & No problem & 97.1 & 98.0 & & NS \\
\hline & Any problem & 2.9 & 2.0 & & \\
\hline \multirow[t]{2}{*}{ Vitality } & No problem & 98.8 & $99 \cdot 5$ & & NS \\
\hline & Any problem & 1.2 & 0.5 & & \\
\hline Sexual activity & No problem & 98.8 & 99.1 & & NS \\
\hline
\end{tabular}




\section{Discussion}

Three outcome measures were used in this study: odds of facing exclusion to health care, knowledge to health indicators related to health promotion, and self-assessed health status. Contrary to previous studies majority of primary outcome measures showed null associations between MFI programmes participation and client's health outcomes via social determinants of health. In exclusion to health care, all but one indicator- in the past six months any member in the family was recommended a surgery but failed to obtain such care - was significantly associated with programme participation. Programme participation was found to be significantly associated to access to surgical care with non-participants more likely to be denied surgical care compared to participants. In other indicators programme participation was found not to be significantly associated with access to care, although there was a tendency for a positive association for hospitalization and sick adult care variables. Our results are contrary to those from previous studies such as the one published by Mohindra et al. (2008). The latter used similar indicators and found MFI to be significantly associated with odds of exclusion to health care. This can be attributed to a well-established primary health care system in Moshi Urban which is available to majority of the population at not more than a kilometre from their home and at affordable cost with minimal barriers to access to care. Furthermore, Moshi urban has high percentage coverage of community based insurance schemes which comprehensively cover for majority of common health conditions except for those with high cost including surgery.

In knowledge to health indicators related to health promotion, contrary to results of previous works such as of Dohn at el. (2004) and Doocy et al. (2005) we found null association between clients and knowledge to health indicators. In our study both clients and non-clients scored high irrespective to programme participation status. In their study, Dohn and colleagues found improvement in all three communities examined with highest changes in communities which had parallel microcredit and health programmes. Absence of other structure intervention such as health and health education in the MFI programme or in nearby communities in Moshi (Kessy et al., 2015), might have undermined the potential effectiveness of the intervention. Most of the studies with positive association with MFI programmes participation have components of either education or health in their programmes to maximize MFI health-promoting capacity (Pronyk et al., 2006; De La Cruz et al., 2009). Null association was also observed in self-health assessment using the $15 \mathrm{D}$ instrument. Self-selection of participants to MFI programmes who are not old, sick, physically or mentally handicapped may result in having a limited effect on $15 \mathrm{D}$ tool.

Limitation to our study are related to its design, that is being a cross sectional study it may lack robustness in results. The design is also liable to placement bias and self, peer, and lender selection of participants (Pitt \& Khandker, 1998). Cross sectional studies suffer selection bias as they compare clients to non-clients whom may differ in unobserved ways such as motivation or sense of entrepreneurship. A randomized controlled trial study could have been ideal. However, there are also difficulties in this because of high penetration of microcredit programmes intervention in our settings which may containment the results (Banerjee et al., 2009). Another limitation was the reliance to self-assessed health status, as previous studies have shown that they are susceptible to perception bias (Sen, 2002).

Despite the positive achievements and the promising potentials of MFI shown elsewhere, programme participation was shown not to be associated with improved health outcomes to programme participants and their families in Moshi, Tanzania. Non-integration of a health and health education components in existing programmes can be highlighted as a limitation factor to the health-promoting capacity of MFI programmes in Moshi. However, the programmes remain a powerful strategy for attaining better health outcomes as shown elsewhere if complemented to synergize its effectiveness. Access to financial services is undeniably important to the poor, but it 
has been shown in Moshi to be insufficient on its own to address the multi-dimensional challenges of poverty including poor health. MFI in Moshi require policies and strategies that will facilitate and enforce integration of health and health education components into their designs to maximize their health-promoting capacity.

\section{Acknowledgements}

The authors are thankful to the Letten foundation of Norway for its financial and technical support in conducting the study and the Municipal directors' office in Moshi for permission to conduct the study in Moshi Urban.

\section{References}

Ahmed, S. (2009) Capacity development among the ultra-poor in Bangladesh: a case study. Journal of Health Population and Nutrition 27:528-534.

Banerjee, A., Duflo, E., Glennerster, R. \& Kinnan, C. (2009) The miracle of microfinance? Evidence from a randomized evaluation. Available from: http://econ- www.mit.edu/files/4162 [Accessed: 18 April 2016].

De La Cruz, N., Crookston, B., Gray, B., Alder, S. \& Dearden, K. (2009) Microfinance against malaria: impact of freedom from hunger's malaria education when delivered by rural banks in Ghana. Transactions of the Royal Society of Tropical Medicine and Hygiene 103: 1229-1236.

Doocy, S., Teferra, S., Norel, D. \& Burnham, G. (2005) Credit program outcomes: coping capacity and nutritional status in the food insecure context of Ethiopia. Social Science \& Medicine 60:2371-382.

Dohn, AL., Chávez, A., Dohn, MN., Saturria L. \& Pimentel, C. (2004) Changes in health indicators related to health promotion and microcredit programs in the Dominican Republic. Revisita Panamericana de Salud Publica 15: 185-93.

Goetz, A., \& Gupta, S. (1996) Who takes the credit? Gender, power, and control over loan use in rural credit programs in Bangladesh. World Development 24: 45-63.

Hammad, B. (2001) On health and wealth. In: R. Rodriguez-Garcia, J.A. Macinko, W.F. Waters (eds). Microenterprise development for better health outcomes. Westport, CT: Greenwood Press, 7 e14.

Kessy, J., Mtamakaya, C., Damian J., Stray-Pedersen, B., Botten, G. \& Msuya, S. (2015) Microfinance and clientele description in Tanzania. Papirex Indian Journal of Research 4(9).

Khandker, S. (2005) "Microfinance and poverty: evidence using panel data from Bangladesh." The World Bank Economic Review 19 (2): 263-286.

Marmot, M. (2007) Achieving health equity: from causes to fair outcomes. Lancet 370: 1153-1163.

Marmot, M., Friel, S., Bell, R., Houweling, T.A.J., Taylor, S; Commission on Social Determinants of Health (2008) Closing the gap in a generation: health equity through action on social determinants of health. Lancet 372:1661-1669

Mohindra, K., Haddad, S. \& Nayaran, D. (2008) Can microcredit help improve the health of poor women? Some finding from a cross sectional study in Kerala, India. International Journal for Equity 7:2.

Pitt, M. \& Khandker, S. (1998) The impact of group-based credit programmes on poor households in Bangladesh: does the gender of participants matter? Journal of Political Economy 106: 958-996.

Pronyk, P.M., Hargreaves, J.R., Kim, J.C., Morison, L.A., Phetla, G., Watts, C., Busza, J. \& Porter, J.D.H. (2006) Effect of a structural intervention for the prevention of intimate-partner violence and HIV in rural South Africa: a cluster randomized trial. Lancet 368: 1973-1983.

Sen, A. (2002) Health perception versus observation. British Medical Journal 324: 860-861. 
Sintonen, H. (2001) The 15D instrument of health-related quality of life: properties and applications. Annals of Medicine 33:328-336.

Smith, S. (2002) Village banking and maternal and child health: evidence from Ecuador and Honduras. World Development 30:707-703.

Sigalla, R. \& Carney, S. (2012) poverty reduction through entrepreneurship: Microcredit, learning and ambivalence amongst women in urban Tanzania. International Journal of Education Development 32:546-554.

TDHS (2011) Tanzania Demographic and Health Survey 2010-11. National Bureau of Statistics and ICF Macro. Calverton, Maryland, USA.

Wamue-Ngare, G. \& Njoroge, N. (2011) Gender Paradigm Shift within the Family Structure in Kiambu, Kenya. African Journal of Social Sciences 1(3):10-20.

Woller, G. \& Woodworth, W. (2001) Microcredit as a grass-roots policy for international development. Policy Studies Journal 29: 267-283.

WHO (2008) Closing the gap in a generation: health equity through action on the social determinants of health Commission on Social Determinants of Health. World Health Organization. http://apps.who.int/iris/bitstream/10665/43943/1/9789241563703_eng.pdf.

URT (2013) Population and Housing Census: Population Distribution by Administrative Areas. National Bureau of Statistics, Ministry of Finance, Dar es Salaam and Office of Chief Government Statistician, President's Office, Finance, Economy and Development Planning, Zanzibar.

Yunus, M. (2002) Toward eliminating poverty from the world: Grameen Bank experience. In: C.L. Anderson \& J.W. Looney (eds). Making Progress: Essays in Progress and Public Policy. Lanham, MD: Lexington Books: 371-8. 